\title{
THE PREY ATTACK BEHAVIOR OF ACHAEARANEA TESSELATA (ARANEAE, THERIDIIDAE)
}

\author{
Gilbert Barrantes and Ju-Lin Weng: Escuela de Biología, Ciudad Universitaria \\ Rodrigo Facio, Universidad de Costa Rica, San Pedro, San José, Costa Rica. \\ E-mail: gbarrantes@biologia.ucr.ac.cr
}

\begin{abstract}
The attack behavior of the cobweb spider Achaearanea tesselata (Keyserling 1884) is roughly separated into three sequential steps: descend from the suspended retreat, pass through the sheet threads, and wrap the prey from underneath the sheet. The position and speed as the spider descended varied apparently according to prey type. In the fastest descent, A. tesselata fell free upside down, with all legs free and stretched upward. Two other relatively slow types of descent occurred when spiders approached the sheet head down or climbing down on a mesh thread. The behavior used to pass between the sheet lines showed little variation. It occurred at high speed with the legs folded dorsally; when the legs were in this position the spider offered a very small area of impact, apparently permitting the femora to penetrate or open a space between the lines of the sheet. The spider then opened the femora of the legs to create enough space for the cephalothorax, and seizing the sheet from underneath with legs I, II, and III, the spider pulled the abdomen and hind legs through the sheet. Then the spider rushed to the prey, flung viscid lines at the prey, and wrapped it. Attacks occurred in as little as $0.11 \mathrm{~s}$ after the spider began its descent.

The design of the webs of A. tesselata transmits information regarding the location of the prey trapped on the sheet to reach the resting spider inside the retreat. The first response of the spider in her retreat was to turn to face the prey; the spider then climbed down along mesh threads following a nearly straight line to the prey.
\end{abstract}

Keywords: Cobweb spider, prey capture, orientation, web use, tangle web, silk

The design of both a spider's web and its attack behavior are likely complementary and together affect prey capture success (Eberhard 1990). Webs generally trap and partially immobilize prey (Chacón \& Eberhard 1980; Nentwig 1982), but usually prey escape unless the spider further immobilizes them (Eberhard 1990). Therefore, prey capture success is partially determined by the speed with which the spider reaches the prey, which in turn is probably largely dependent on the information the spider receives regarding prey location in the web (Biere \& Uetz 1981). The speed and complexity of attack behavior may be at least partially related to the web design (Eberhard 1990), since some webs may impose some restriction on the spider's movements.

Achaearanea tesselata (Keyserling 1884) is relatively common in bushes in urban areas and highly disturbed vegetation throughout its distribution in Central and South America (Levi 1959; Eberhard 1972). The web of this spider consists of a finely-spun horizontal sheet, with a dense mesh above and a few support lines below (Fig. 1, Eberhard 1972). A curled leaf, tiny twigs, small dried flowers, or other debris serve as the spider's retreat in nearly all webs. The spider rests upside down within the retreat, which is suspended near the middle of the upper mesh. The web of A. tesselata works as a knock down trap for flying and jumping insects. Insects that strike the upper mesh fall down onto the sheet where they are attacked by spiders. Jörger and Eberhard (pers. comm.) suggested that lines in the mesh of A. tesselata could also offer information to spiders regarding prey location in the web. The design of this web is apparently shared by two other species in the genus: A. disparata Denis 1965 (Darchen 1968) and A. japonica (Bosenberg \& Strand 1906) (= Theridium japonicum). However, A. tesselata seems to be unique in resting above the sheet and passing through it to attack prey (Eberhard 1972).

According to Eberhard (1972), the first response of A. tesselata to prey in its web was 


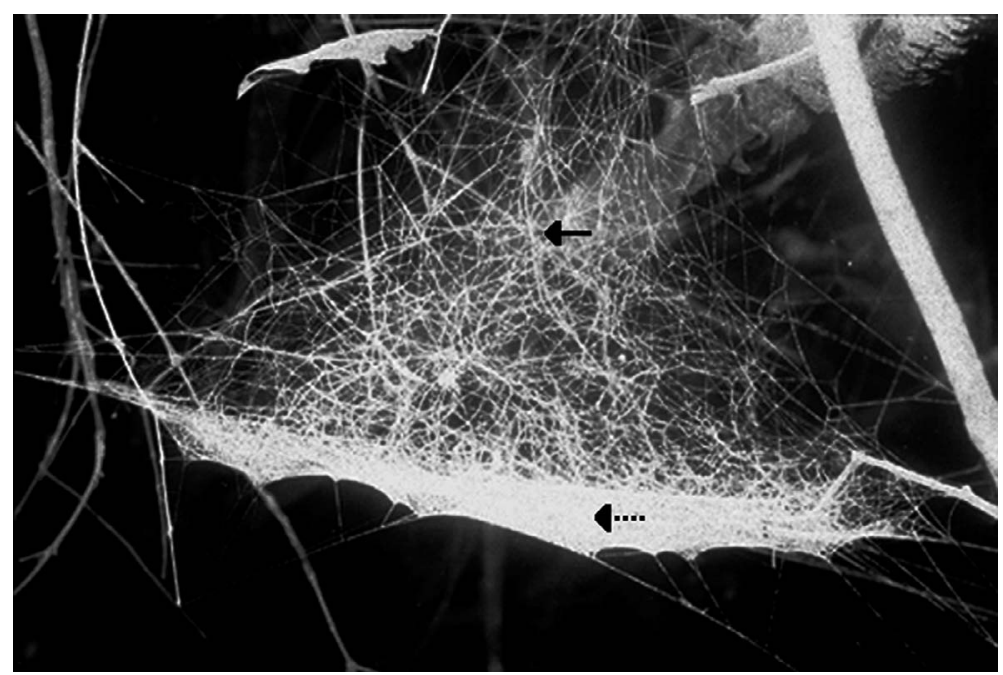

Figure 1.-Web of A. tesselata: notice the upper mesh (solid arrow) and the sheet (dotted arrow).

to descend from the retreat. Passing rapidly through the sheet without causing any apparent damage, the spider rushed directly to the prey wrapping and/or biting it. Considering the high density of threads in the sheet (Eberhard 1972; Jörger \& Eberhard pers. comm.), it is puzzling how the spider passes so rapidly through the sheet and how this structure suffers no apparent damage. In this paper we describe in detail how $A$. tesselata descends from the retreat and passes through the sheet and discuss the advantages and possible evolution of this behavior. Furthermore, we test the hypothesis that the upper mesh lines give information regarding prey position on the sheet to the spider.

\section{METHODS}

Field observations.-Observations on attack behavior of $A$. tesselata were made in the field, from March to September 2004, within the campus of the Universidad de Costa Rica, San Pedro, San José Province, Costa Rica $\left(9^{\circ} 54^{\prime} \mathrm{N}, 8^{\circ} 03^{\prime} \mathrm{W}\right.$; elevation $\left.1200 \mathrm{~m}\right)$. Attack behavior of A. tesselata occurs so rapidly that the spider's descent and details of its movements as it passes through the sheet cannot be distinguished with the naked eye. Thus, in addition to field observations, we video recorded the complete attack sequence of 37 adult females of $A$. tesselata in the field; each individual was recorded from one to four times, giving a total of 52 sequences. Video recordings were made with a digital video camera
(Sony DCR-VX 1000) that recorded 30 frames/s.

Detailed descriptions of attack behavior are based on video analyses. Drawings are based on digital-video images imported into a computer using the program iMovie, version 2.0. Different portions of the spider were not always in focus, hence sample sizes for different analyses differed. Descriptions are all based on samples of at least 10 individuals, sample sizes lower than 10 are indicated in the text.

Density of sheet threads.-We estimated the density of threads in sheets of five webs of adult females by counting the number of threads crossing the diameter of the $1.82 \mathrm{~mm}$ field of view of a sample on a glass microscope slide under a compound microscope. Threads were counted from 10 to 15 fields of view in each of the five sheets and then the average number of threads per millimeter was calculated. Samples from the sheets were collected on slides framed with strips of doublesided adhesive tape $(1.5 \mathrm{~mm}$ thick $\times 2.5 \mathrm{~mm}$ wide). Slides were carefully lifted from below the web into the threads of the sheet; the threads extending beyond the slide were cut so that only threads adhering to the tape were collected. This method allows observation of threads without modifying their original arrangement. Additionally, on each of these slides, we randomly selected 10 sheet lines of approximately $10 \mathrm{~mm}$ long. Along each selected line, thread connections and number of 
threads crossing over, but not attached to the line were counted in 10 fields of view $(0.45$ $\mathrm{mm}$ each). The width and length of the cephalothorax and abdomen were also measured on 30 adult females of $A$. tesselata for comparison with thread density of sheets (14 from the collection of the Museo de Zoología, Universidad de Costa Rica, and 16 used in a prey location experiment). Voucher specimens of spiders have been deposited in the Museo de Zoología, Universidad de Costa Rica.

Experiments on orientation and descending speed.- Sixteen mature females with retreats and egg sacs were each placed on a three-dimensional wire structure with six extensions projected downward, forming a hexagon, hanging from a thin fishing line at $2 \mathrm{~m}$ above the floor. The fishing line makes it difficult for the spiders to escape upward as they cannot climb it. They frequently descend, but usually at about a meter they turn back if they have not encountered an object below. The retreats in the webs of these spiders were small enough to allow observations of the movements of the spider inside. After one or two nights spiders had spun a complete web with the sheet approximately following the hexagonal shape of the three-dimensional structure.

To determine the orientation of the spiders during the attack behavior, we dropped Drosophila sp. flies on the sheets of the finished webs and video recorded the spider's movements in the retreat and its orientation as it approached the prey. To video record spider's movements the camera was fixed to a platform with the lens at $10 \mathrm{~cm}$ above the retreat and aligned perpendicular to its top. Before each attack, we randomly selected one of the six sections of the approximately hexagonal sheet on which the prey was to be dropped. Each spider was recorded only once. We applied a binomial analysis to evaluate if the attack approach of the spider was random with respect to the six segments of the sheet. More precise measurements of the attack orientation of the spider were obtained from video records; specifically we obtained the difference in degrees of the approaching direction of the spider to the prey and prey position in the sheet. We compared the mean differences between approaching direction and prey position using a random distribution of means. This distribution was constructed under the assumption that the attack direction of spiders was ran- dom, hence the deviation from the prey position could vary from $0^{\circ}$ (no deviation from prey position) to $180^{\circ}$ (maximum deviation from prey position). We used a Monte Carlo Analysis (Statistica package, version 5.0) to produce 500 random samples of possible deviation angles. The mean of departure angles of A. tesselata was compared with a distribution of random means using a one sample Student's t-test. We complemented the information obtained in the laboratory with field observations on spiderlings and adult female orientation.

We also measured the time a spider spent in descending from the retreat to the sheet and the attack time from the retreat to the moment the attack of the prey began. Time was estimated from the video records of different spiders using a frame (30 frames/s) as a timereference unit. Times were compared among descent and prey types using one way ANOVAs. Velocity of descent was calculated for 15 webs in which a house fly or a blow fly of similar size was dropped in the center of the sheet. The descent time was estimated in all cases from the video records and the distance from the retreat to the sheet was measured to calculate the velocity. We also calculated the free fall velocity by dropping two recently dead mature females. These spiders were frozen until dead, and then allowed to thaw. We next dropped and recorded the falling time for each spider from a platform placed at $5.5 \mathrm{~cm}$ above a landing surface; we repeated this three times for each spider.

\section{RESULTS}

Orientation in retreat and mesh.-The first response of A. tesselata in the retreat to a Drosophila dropped onto the sheet was to turn to orient facing "toward" the same sector of the sheet. The orientation movements of spiders in the retreat occurred in all 16 trials conducted in the laboratory: four times prey was in front of the spider, six times it was lateral to her, and six times behind her. While descending to Drosophila prey, spiders climbed down along the mesh lines, following a nearly straight line. In 15 out of 16 times the spider moved to the $60^{\circ}$ section of the sheet on which a prey was dropped $(P<$ 0.0001 , Binomial test). The average angle deviation of spiders to prey location at arrival to the sheet was $7.0^{\circ}(8.2)$. This small deviation 


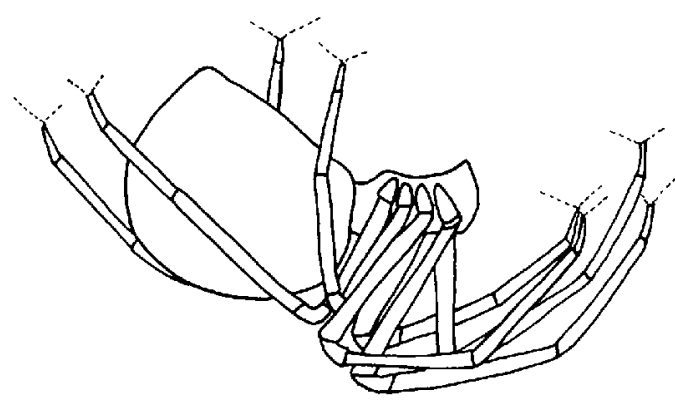

Figure 2.- Resting position of A. tesselata in a retreat; retreat was not drawn to show the position of the legs (dash lines indicate the possible position of threads from which the spider hangs).

is significantly smaller than a random mean $(87.6 \pm 48.51 ; t=-9.87, d f=15, P<$ $0.0001)$. The lines on which A. tesselata descended probably intersected several other threads, since the upper mesh in the web is relatively dense and lines are interconnected, but the spiders continued apparently selecting the lines running more directly toward the prey. We could not, however, see the lines in most cases. On three occasions we could see that the spider paused briefly at an intersection of lines; she briefly jerked the threads with her legs I, and then moved on the line that ran most nearly toward the prey.

In the field we video recorded the orientation behavior of three fourth or fifth instar juveniles on their mother's web. The spiderlings were on threads about three centimeters to the side and two centimeters below the retreat when a Drosophila was dropped on the sheet $5 \mathrm{~cm}$ away on the opposite sector of the sheet. The spiderlings did not descend directly to the sheet, but walked directly toward the prey through the mesh, passing under the retreat.

Position in the retreat.-The spider hung inside the retreat (if present; Fig. 2), above the sheet, where several threads converged from the mesh. The longitudinal plane of the spider formed an angle of $30^{\circ}\left(\mathrm{SD} \pm 6^{\circ}, n=3\right)$, relative to the sheet, with the cephalothorax directed downward, and dorsum facing the sheet (Fig. 2). Given the position of the legs, it is likely that A. tesselata hangs from at least four or five different threads while in the retreat.

Descending behavior.-The position of the body and legs when A. tesselata came down from the retreat, after a prey falls on the sheet, varied between individuals and within the same spider depending on prey type, and possibly on hunger and experience of the spider. Relatively large flies (e.g., house flies) released the fastest reaction from the spider, provoking a very fast descent to the sheet (Table 1). Treehoppers, of about the size of a housefly, evoked a relatively slow descent; similar reactions were elicited by Drosophila. The variation fits relatively well into three categories: free fall, head-down, and walking on mesh threads.

Free fall: The spider fell rapidly while upside down (dorsum toward the sheet) with all legs apparently directed upward. Falls were so rapid $(52.3 \mathrm{~cm} / \mathrm{s}, \mathrm{SD}=13.8$, range $=30.3-$ 80.0; Table 1) that the spider was generally a blur in the video (Figs. 3-6). The spider frequently bounced when her body first struck the sheet, but sometimes passed through on first contact. When this type of descent occurred, hind legs apparently did not contact the dragline. The falling speed of dead spiders measured in the laboratory was similar to the speed calculated for spiders in the field (54.1 $\mathrm{cm} / \mathrm{s}, \mathrm{SD}=5.6$ ). However, field data may be affected by wind currents, which reduce the speed, and by different weights of spiders. In addition, the spider was apparently capable of directing her descent toward the prey position as she fell. The Figures 3-6, obtained from a

Table 1.-Average time (standard deviation in parentheses) spent by Achaearanea tesselata descending from the retreat to the sheet web and attacking prey. Time of attack includes from the moment the spider initiates its descent to the moment the attack begins. Information is separated by descent type; units in seconds.

\begin{tabular}{lllllll}
\hline & \multicolumn{9}{c}{ Descent type } \\
\cline { 2 - 7 } & \multicolumn{1}{c}{ Free fall $(n=21)$} & \multicolumn{2}{c}{ Head down $(n=10)$} & \multicolumn{2}{c}{ Walking $(n=15)$} \\
\hline Descent & 0.11 & $(0.02)$ & 1.36 & $(0.65)$ & 4.08 & $(3.46)$ \\
Attack & 1.54 & $(1.42)$ & 4.64 & $(5.41)$ & 5.86 & $(5.45)$ \\
\hline
\end{tabular}



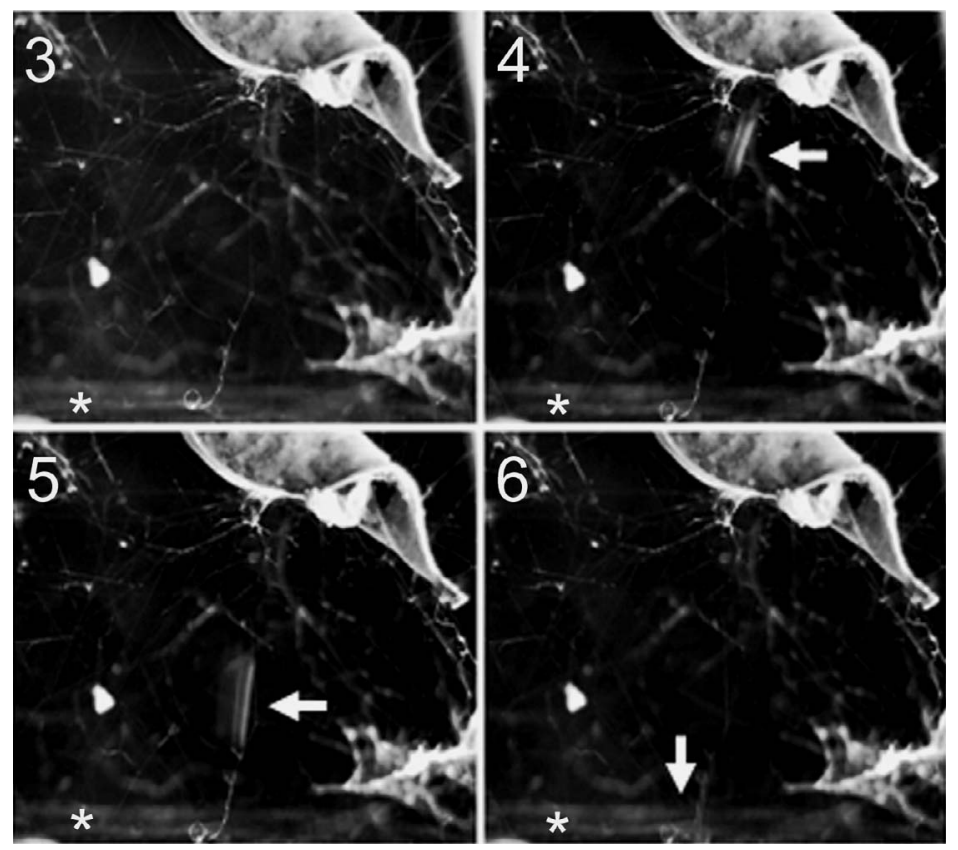

Figures 3-6.-Sequence of events during the free fall descent of A. tesselata. 3. The spider inside the retreat. 4. The spider beginning to fall (blur indicated by the arrow). 5. Note that the spider is only a blur due to the descent speed (arrow). 6. Point where spider struck the sheet (arrow). Note the angle of falling direction of the spider toward the left of the picture where the prey contacted the sheet (indicated by a star).

video record taken in the lab to avoid wind currents, shows how the spider oriented her fall toward the prey position (left-inferior corner of the picture). From video records, it was not possible to obtain information on how such orientation was attained by falling spiders.

Head down: The spider advanced more slowly toward the sheet maintaining a more or less head-down position (Table 1, Figs. 7$8)$. The spider advanced in short jerks: it first extended the anterior and second pair of legs forward and, waving them, possibly grabbed some mesh threads and moved downward a short distance. This sequence was repeated several times until the spider reached the sheet. In this descent the spider moved almost perpendicularly to the sheet through the mesh, possibly using its lines as "the steps of a ladder'. During this type of descent the spider alternated the leg IV that held the dragline.

Walking on mesh threads: A. tesselata approached the sheet by walking directly toward the prey along one or a few mesh threads. In this descent the spider's body was oblique rel- ative to the sheet plane. While walking, the spider moved forward and alternately extended her anterior legs, while one leg IV held the dragline. This type of descent was much more frequent when prey fell near the edge of the sheet.

Crossing through the sheet threads.The spider passed her body through the sheet threads with a series of extraordinarily rapid movements of legs and body that enabled her to ease her relatively large body (Table 2) through the small spaces between the sheet lines (Table 3). The movements of the spider were so rapid that it was necessary to use 32 video records of attack behavior to assemble the complete sequence of movements as the spider passed through the sheet. In all cases, independently of how she arrived at the sheet, the spider passed this structure dorsal side first. Hence, when the spider descended either head down or walking along mesh threads, she repositioned her body before passing through the sheet. In these cases, when the spider was nearly touching the sheet, she extended her first legs and grabbed a sheet line 


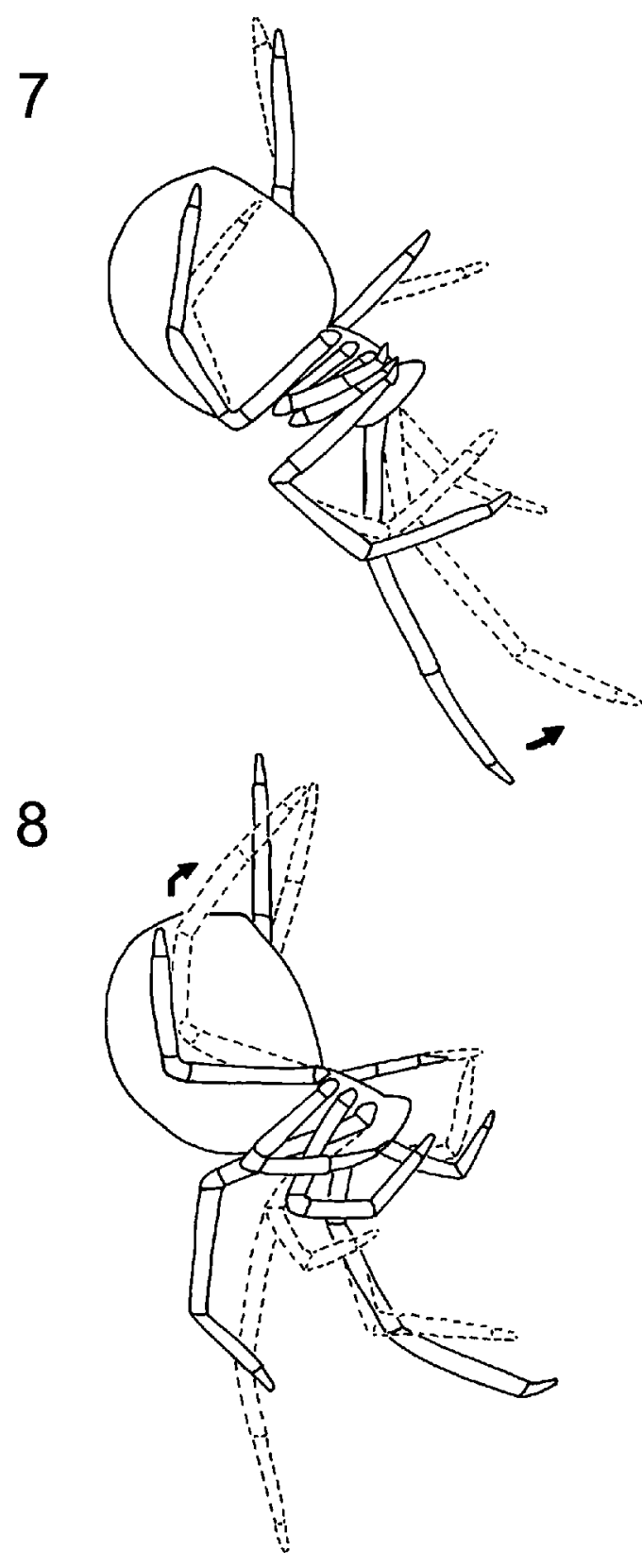

Figures 7-8.-Position and movements of the legs of A. tesselata in a head-down descent. 7. Extending legs I-II and waving them to grab some mesh threads. 8. Movement of legs as the spider descended a short distance.

with each one (Fig. 9), and then pulled these threads toward her body by folding the first legs. The sheet threads she had grabbed were bent toward the spider's body, but she was not

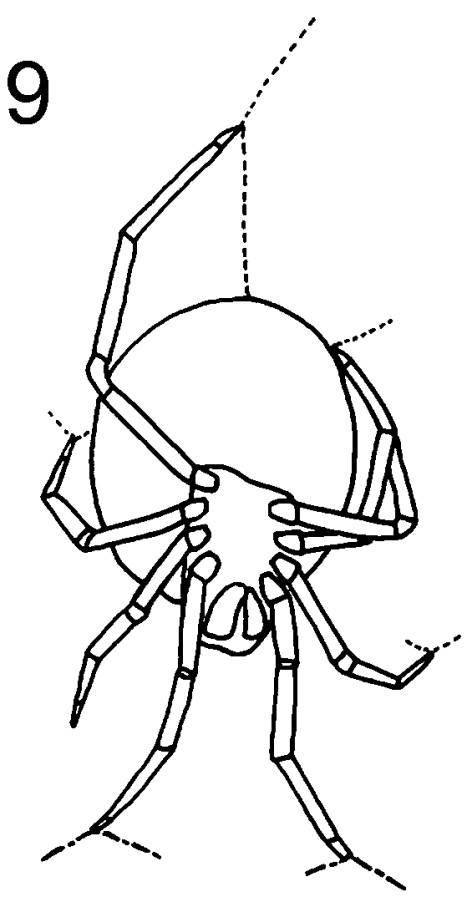

Figure 9.- - Ventral view of A. tesselata pulling sheet lines with her first legs. Note most of the other legs directed backwards and grabbing mesh threads to possibly counteract the forward tension exerted by pulling sheet threads.

dragged forward, indicating that the tension was counteracted by tension on mesh threads held by the other legs, which were directed backward, except one hind leg that was in contact with the dragline (Fig. 9). From this position, A. tesselata released all but the first legs at once, falling in a very fast movement (ca. $0.03 \mathrm{~s}$ ), dorsum against the sheet (Figs. 10-11).

Independently of how the spider descended from the retreat, as she passed through the sheet, her legs were tightly folded against the body, forming a compact structure that likely

Table 2.-Length and width of abdomen (Ab) and cephalothorax $(\mathrm{Cph})$ in millimeters for $30 \mathrm{ma}-$ ture females of Achaearanea tesselata.

\begin{tabular}{lcccc}
\hline & $\begin{array}{c}\text { Ab } \\
\text { length }\end{array}$ & $\begin{array}{c}\text { Ab } \\
\text { width }\end{array}$ & $\begin{array}{c}\text { Cph } \\
\text { length }\end{array}$ & $\begin{array}{c}\text { Cph } \\
\text { width }\end{array}$ \\
\hline Average & 3.1 & 2.3 & 1.8 & 1.4 \\
S. D. & 0.39 & 0.23 & 0.10 & 0.07 \\
Range & $2.6-3.7$ & $2.0-2.6$ & $1.7-2.0$ & $1.3-1.5$ \\
\hline
\end{tabular}




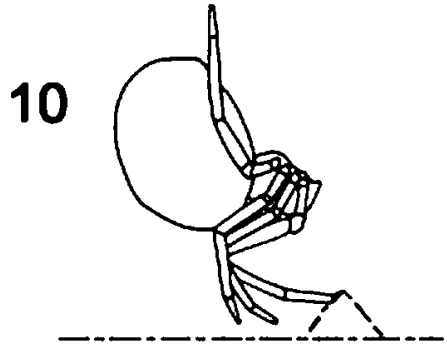

12

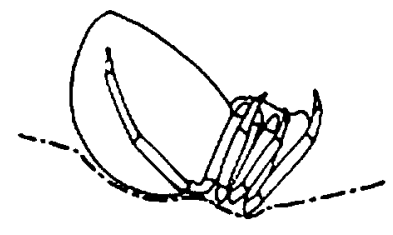

14

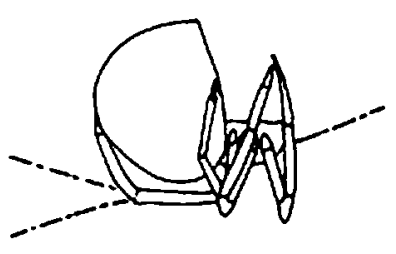

16

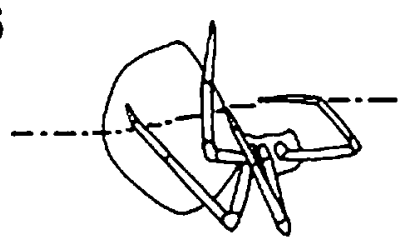

11

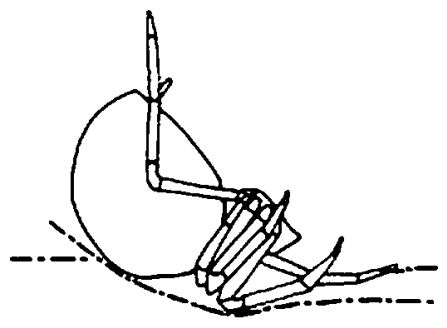

13

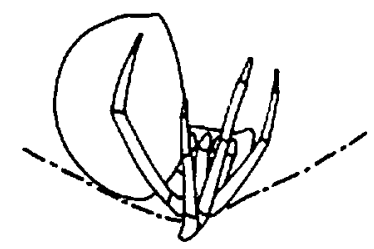

15

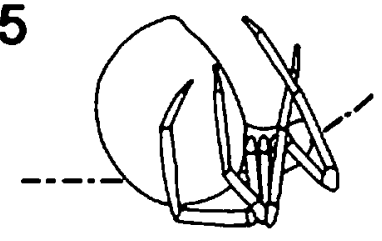

17

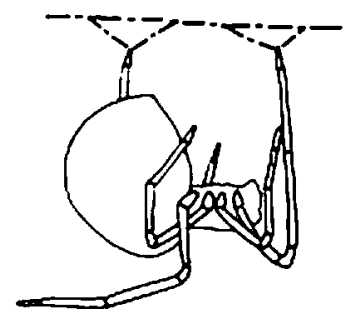

Figures 10-17.- Sequence of movements and position of legs of A. tesselata passing through the sheet. (Lines represent the approximate position of the sheet; threads grabbed by spider's legs in 10 and 18 were clearly observed in the video records. All legs were not always drawn when video images were not focused or angle did not allow a clear view). 10. The spider falling on the sheet after releasing its grasp on mesh threads. 11. The spider contacting the platform as she falls, note how legs began to fold on the cephalothorax. 12. The platform is deformed by the impact of the spider, the legs of the spider are tightly folded 
Table 3.- Average of attachment points and unattached lines crossing over along 10 randomly selected lines in five different sheets; counts were obtained in 10 fields of view $(0.45 \mathrm{~mm}$ each $)$ per sheet. Mean density of sheet lines per mm calculated as number of lines across 10 to 15 fields of view (1.82 $\mathrm{mm}$ each) for five different sheets.

\begin{tabular}{lccc}
\hline & $\begin{array}{c}\text { Attachment } \\
\text { points }\end{array}$ & $\begin{array}{c}\text { Unattached } \\
\text { lines }\end{array}$ & Density \\
\hline Average & 1.15 & 1.60 & 1.96 \\
S. D. & 0.61 & 0.80 & 0.59 \\
Range & $0.58-2.16$ & $1.08-3.00$ & $0.52-3.85$ \\
\hline
\end{tabular}

facilitated penetration between the dense woven threads of the sheet (Fig. 12; Table 3). Femora (and possibly coxae and trochanters) of legs I, II, and III of both sides were directed dorsally over the cephalothorax, nearly touching the anterior surface of the abdomen. The femur-patella joints touched or nearly touched each other and the more distal segments were pointed ventrally with tarsus and metatarsus (possibly for legs I and II) bent over the cephalothorax (Fig. 12). The femora of legs IV were approximately parallel to the others, but the more distal segments of these legs were directed backward and pressed against the sides of the abdomen (Fig. 12); one leg IV held the dragline.

The spider struck the sheet with the folded legs resting against the cephalothorax first, while her abdomen was bent upward at an angle of $30^{\circ}$ ( $\mathrm{SD}=5^{\circ}, n=3$; Figs. 11-12). As the spider contacted the sheet, femur-patella joints of possibly all legs were apparently pushed through a space between the sheet threads (Fig. 13). Then, the femora of all legs began to stretch out laterally, widening the space between threads of the sheet to permit the cephalothorax to pass through (Fig. 1415). During some of these movements the distal segments of legs IV were maintained apparently immobile and pressed against the abdomen, which was still above the sheet
(Figs. 12-13). Then the spider grabbed some sheet threads from underneath with legs I, II, and III and pulled herself downward, pulling and freeing first the legs IV (Fig. 16), which grabbed some lines as soon as they passed through the sheet. The spider continued pulling, by stretching the legs ventrally, and dragged the abdomen through the sheet and then hung with some legs free (Fig. 17) before rushing toward the prey. In a few occasions, the spider showed some difficulty dragging the abdomen through the sheet so that she had to struggle to free her abdomen from the lines. The entire process of passing through the sheet took from 0.03 to $0.20 \mathrm{~s}$ (mean $=0.10$, $\mathrm{SD}=0.06, n=12$ ).

Capturing and transporting prey.-As soon as the spider was hanging from the sheet lines, she rushed directly to the prey that rested on the sheet. With the prey at reach, the spider began the attack by flinging lines with large viscid globs up onto it with her fourth tarsi (Griswold et al. 1998). Immediately after the first attack, A. tesselata started wrapping the prey, pausing frequently to either bite it or clean the tarsi of legs IV, whereas the other legs grabbed sheet lines from below. When a large prey was fully wrapped, the spider rapidly broke some sheet threads, attached a dragline by pressing the spinnerets to the prey and pulled it up to the retreat with a fourth leg, climbing up along a mesh line. The dragline was frequently attached half way to the retreat, and the spider climbed down by the same line, completely releasing the prey from the sheet threads, wrapping the prey with a few more lines, and attaching another line, pulled up the prey closer to the retreat. This procedure was repeated until the prey was at about $1 \mathrm{~cm}$ from the retreat. If the prey was small, the spider directly carried it up nearby the retreat with one hind leg. Occasionally, a prey escaped before the spider reached it ( $n$ $=6$ ). In such cases, spiders returned to the retreat passing back upward through the sheet.

$\leftarrow$

on the cephalothorax, except distal segments of legs IV that are pressed against the sides of the abdomen. 13. Joints femur-patella-tibia of all legs passing through the sheet. 14. Femora begin to stretch out, opening enough space to seize the cephalothorax through the sheet. 15. Femora widely stretched. 16. Most legs grabbing sheet threads from underneath, the abdomen half way passing the sheet. 17. The spider hanging from the underside of the sheet. 
The process was slow and clumsy. The spider introduced different legs into different spaces between the sheet lines, making it difficult to pass through. Usually she only succeeded after several attempts, and cut and broke some lines before getting free.

Time spent during the descent and attack.- The time the spider spent descending from the retreat to the sheet was determined by how the spider approached the sheet. The average time that the spider spent in a free fall descent was significantly lower than the time she spent in a head down or walking descent $\left(F_{2,43}=17.48, P<0.0001\right.$; Table 1$)$. Accordingly, the mean time from the moment the spider began her descent until the moment the attack (attack time) of the prey began was significantly lower when she fell free from the retreat $\left(F_{2,43}=5.29, P<0.01\right)$. However, differences in attack time are primarily related to the lower time of free fall descents, since the time the spider lasted from the moment she contacted the sheet to start attacking the prey did not differ among spiders using different descent types $\left(F_{(2,38)}=1.74, P=0.19\right)$.

The type of prey apparently determined how the spider descended from the retreat to the sheet. For example, free fall was more frequent when prey were blow flies or house flies, walking along lines when prey were drosophilids, and head down descents were more frequent when prey were treehoppers $\left(\chi^{2}=\right.$ 42.4, $d f=4, P<0.0001)$.

Prey entangled in mesh lines.-Occasionally a prey was entangled in mesh lines at about the same level of the retreat $(n=4)$. When this occurred the spider descended, passed through the sheet, and shook it from underneath, apparently trying to determine the prey's location. After a few seconds the spider climbed through the sheet into the mesh. The movements as she climbed in the mesh were clumsy and her orientation toward the prey imprecise, compared with the rapid and precise movements when locating prey on the sheet.

\section{DISCUSSION}

Horizontal aerial sheets with mesh above and/or below have independently evolved in a wide variety of separated spider groups (Shear 1986; Eberhard 1990). In some families (e.g., Linyphiidae) the spiders run upside down on the lower surface of the sheet (Bristowe 1958;
Griswold et al. 1998; Benjamin et al. 2002; Benjamin \& Zschokke 2004), but in other families (e.g., Lycosidae, Pisauridae) the spider runs on top of the sheet to reach the prey (Eberhard 1990). Theridiidae webs with aerial sheets are present in some Anelosimus, Tidarren and Achaearanea, e.g., A. disparata, A. tesselata, and A. japonica (Darchen 1968; Eberhard 1972; Shinkai \& Takano 1984). However, the attack behavior associated with the presence of a sheet in the web is very different between genera and species. Some social species of Anelosimus attack prey from below the platform (Levi 1972), similar to some Tidarren (pers. obs.), other Anelosimus that build sheets with knockdown lines, attack insects entangled either in trap lines or in the sheet (Avilés \& Salazar 1999; Vakanas \& Krafft 2001). In Achaearanea, the spiders of the social species $A$. disparata descend directly from the retreat to the prey on the sheet without passing through this structure to access prey (Darchen 1968; Darchen \& Ledoux 1978) contrary to A. tesselata; no information is available for A. japonica.

The unusual web design probably has likely shaped, at least partially, the evolution of the complex attack behavior of A. tesselata. Many Achaearanea species construct three-dimensional gum-foot webs, specialized for walking prey and/or working as knock down traps (Gertsch 1949); this type of web is ancestral in Theridiidae (Levi \& Levi 1962; Benjamin \& Zschokke 2003; Agnarsson 2004). Similarly, the presence of a retreat suspended in the upper mesh is common in species of Achaearanea, and is also a feature present in other genera, such as Tidarren and Theridion (Bristowe 1958; Agnarsson 2003). Falling upside down from the retreat also occurs as an escape response in Argyrodes (Whitehouse 1986), A. lunata (Clerck 1757) $(=T$. lunatum) (Nielsen 1932), A. tepidariorum (C. L. Koch 1841) and in Tidarren sp. (G. Barrantes unpubl. data) when spiders are disturbed, suggesting that this behavior is also widespread in theridiids. Therefore, the construction of a sheet in Achaearanea seems to be newly evolved. Thus, A. tesselata, retaining the theridiid retreat trait, presents a novel behavior that allows her to pass through the sheet and access prey from underneath; this novel behavior probably derived from a former escape behavior. 
Some elements of the sequence of the attack behavior were fairly variable such as the descent to approach the prey, while the position of legs and body when the spider passed through the sheet showed very little variation. The speed and movements of this spider when the prey is approached seemed to be determined primarily by the size and type of prey, though position of prey on the sheet and hunger may also determine attack speed (Riechert \& Luczak 1982). Highly rewarding harmless prey with high probability of escaping (e.g., houseflies) released the fastest reaction: free fall descent (Table 1). When the prey was a treehopper, the approach was slow. The strong kicks from the hind legs of treehoppers can probably cause serious injuries to spiders. The harmless drosophilids were also approached slowly, possibly as a consequence of the little reward these prey represent to mature females of A. tesselata. This indicates that A. tesselata is either capable of sensing prey type and how dangerous the prey could be, and of modifying the capture sequence accordingly (Riechert \& Luczak 1982); or it may attack faster prey sending strong signals (e.g., high buzzing) as they may have greater reward.

The spiders' consistent positions while passing through the sheet are probably a response to the high density of threads in this structure relative to the size of the spider. The position of the body and legs when striking the sheet offered the least contact area, and the high speed at the moment of impact (even after a slow descent) may help to insert femurpatella joints between two threads and open enough space for the spider to pass through. The absence of perceptible damage caused to the sheet during an attack, reported by Eberhard (1972), is largely determined by the numerous unattached lines that form part of this structure (Table 3). These lines are probably easily separated when spiders strike the sheet. The consistent orientation of the body, positions of the legs, and behavior as the spider passed down through the sheet largely contrasted with the inconsistent uncoordinated movements of the spider going upward through the sheet after an unsuccessful attack. Intense selection on prey capture success may have reduced variation in downward movements to increase the rapidity of attack (Eberhard 2000). An obvious advantage of attacking prey from underneath is to interpose a protective barrier between the spider and the prey.

The tangled mesh of the web of A. tesselata transmits precise information on prey location to the spider in her retreat. Spiderlings are also capable of perceiving prey location through information transmitted by mesh lines. This is probably due to the convergence of most mesh lines that connect with the sheet below on five or six more or less horizontal threads attached to the mouth of the retreat where the spider hangs (Jörger \& Eberhard pers. comm.). This structure may channel vibrations to the central point where the spider rests. Probably information is yielded by vibrations or changes in tension produced by the prey, as occurs in Latrodectus (Lamoral 1968). This information allowed the spider to orient her attack before initiating her descent. In contrast, information of prey position was not efficiently transmitted to the spider when prey fell and entangled on mesh lines, as the spider's orientation was imprecise. The reason for this imprecision, in terms of thread connection, is not clear. Thus the design of the mesh in A. tesselata may increase efficiency of capture success of prey trapped on the sheet.

The diversity on web designs and frequent convergences in the Theridiidae (Benjamin \& Zschokke 2003; Agnarsson 2004) offer an opportunity to study the interrelation of web design and attack behavior. For example a comparative study of Achaearanea species with similar web design, could provide a better understanding of the evolution of the attack behavior in the genus, and the function of the upper mesh in transmitting information on prey location.

\section{ACKNOWLEDGMENTS}

We thank W.G. Eberhard, I. Agnarsson, G. Stratton, and two anonymous reviewers for their valuable comments on the manuscript. We are indebted to W.G. Eberhard for providing references and the picture of an A. tesselata web, but particularly for his intellectual stimulus throughout this study. We owe the design of slides to collect web samples to the generosity of C. Grismado.

\section{LITERATURE CITED}

Agnarsson, I. 2003. The phylogenetic placement and circumscription of the genus Synotaxus (Araneae: Synotaxidae), a new species from Guya- 
na, and notes on theridioid phylogeny. Invertebrate Systematics 17:719-734.

Agnarsson, I. 2004. Morphological phylogeny of cobweb spiders and their relatives (Araneae, Araneoidea, Theridiidae). Zoological Journal of the Linnaean Society 141:447-626.

Avilés, L. \& P. Salazar. 1999. Notes on the social structure, life cycle, and behavior of Anelosimus eximius. Journal of Arachnology 27:497-502.

Benjamin, S.P. \& S. Zschokke. 2002. Untangling the tangle-web: web construction behavior of the comb-footed spider Steatoda triangulosa and comments on the phylogenetic implications (Araneae: Theridiidae). Journal of Insect Behavior 15:791-809.

Benjamin, S.P. \& S. Zschokke. 2004. Homology, behaviour and spider webs: web construction behaviour of Linyphia hortensis and L. triangularis (Araneae Linyphiidae) and its evolutionary significance. Journal of Evolutionary Biology 17: 120-130.

Benjamin, S.P., M. Düggelin \& S. Zschokke. 2002. Fine structure of sheet-webs of Linyphia triangularis (Clerck) and Microlinyphia pusilla (Sundevall), with remarks on the presence of viscid silk. Acta Zoologica 83:49-59.

Biere, M. \& G. Uetz. 1981. Web orientation in the spider Micrathena gracilis (Araneae: Araneidae). Ecology 62:336-344.

Bristowe, W.S. 1958. The World of Spiders. Willmer Brothers and Haram Ltd., London. 308 pp.

Chacón, P. \& W.G. Eberhard. 1980. Factors affecting numbers and kinds of prey caught in artificial spider webs, with considerations of how orb webs trap prey. Bulletin of the British Arachnological Society 5:29-38.

Darchen, R. 1968. Ethologíe d'Achaearanea disparata Denis, Aranea, Theridiidae, araignée sociale du Gabon. Extrait de la Revue Biologia Gabonica. 4:5-25.

Darchen, R. 1978. Achaearanea disparata, araignée sociale du Gabon, synonyme ou espece jumelle d A. tessellata, solitaire. Revue Arachnologique 1:121-132.

Eberhard, W.G. 1972. Observations on the biology of Achaearanea tesselata (Araneae: Theridiidae). Psyche 79:209-212.

Eberhard, W.G. 1990. Function and phylogeny of spider webs. Annual Review of Ecology and Systematics 21:341-372.

Eberhard, W.G. 2000. Breaking the mold: behavioral variation and evolutionary innovation in
Wendilgarda spiders (Araneae: Theridiosomatidae). Ethology Ecology and Evolution 12:223235.

Griswold, C.E., J.A. Coddington, G. Hormiga \& N. Scharff. 1998. Phylogeny of the orb-web building spiders (Araneae, Orbiculariae: Deinopoidea, Araneoidea). Zoological Journal of the Linnean Society 123:1-99.

Lamoral, B.H. 1968. On the nest and web structure of Latrodectus in South Africa, and some observations on body colouration of $L$. geometricus (Araneae:Theridiidae). Annals of the Natal Museum. 20:1-14.

Levi, H.W. 1959. The spider genera Achaearanea, Theridion and Sphyrotinus from Mexico, Central America and West Indies (Araneae, Theridiidae). Bulletin of the Museum of Comparative Zoology 121:57-163.

Levi, H.W. 1972. Taxonomic-nomeclatorial notes on misplaced theridiid spiders (Araneae: Theridiidae) with observations on Anelosimus. Transactions of the American Microcopical Society 91:533-538.

Levi, H.W. \& L.R. Levi. 1962. The genera of the spider family Theridiidae. Bulletin of the Museum of Comparative Zoology 127:1-71.

Nentwig, W. 1983. The non-filter function of orbwebs in spiders. Oecologia 58:418-420.

Nielsen, E. 1932. The Biology of Spiders with Especial Reference to the Danish Fauna. Volumes $1 \&$ 2. Levin \& Munksgaard, Copenhagen, Denmark. 723 pp.

Riechert, S.E. \& J. Luczak. 1982. Spider foraging: behavioral responses to prey. Pp. 353-386. In Spider Communication: Mechanisms and Ecological Significance (P.N. Witt \& J.S. Rovner, eds.). Princeton University Press, New Jersey.

Shear, W.A. 1986. The evolution of web-building behavior in spiders: a third generation of hypotheses. Pp. 364-400. In Spiders-Webs, Behavior, and Evolution (W.A. Shear, ed.). Stanford University Press, Stanford, California.

Vakanas, G. \& B. Krafft. 2001. Coordination of behavioral sequences between individuals during prey capture in a social spider, Anelosimus eximius. Journal of Insect Behavior 14:777-798.

Whitehouse, M.E.A. 1986. The foraging behaviours of Argyrodes antipodiana (Theridiidae), a kleptoparasitic spider from New Zealand. New Zealand Journal of Zoology 13:151-168.

Manuscript received 17 August 2005, revised 12 July 2006. 